BMJ Open

Diabetes

Research

\& Care

\section{Impact of an individualized type 2 diabetes education program on clinical outcomes during Ramadan}

To cite: McEwen LN, Ibrahim M, Ali NM, et al. Impact of an individualized type 2 diabetes education program on clinical outcomes during Ramadan. BMJ Open Diabetes Research and Care 2015;3:e000111. doi:10.1136/bmjdrc-2015000111

Received 24 April 2015 Revised 22 May 2015 Accepted 29 May 2015

CrossMark

For numbered affiliations see end of article.

Correspondence to Dr Laura N McEwen; Imattei@med.umich.edu

\begin{abstract}
Laura N McEwen, ${ }^{1}$ Mahmoud Ibrahim, ${ }^{2}$ Nahed M Ali, ${ }^{3}$ Samir H Assaad-Khalil, ${ }^{4}$ Hyam Refaat Tantawi, ${ }^{5}$ Gamela Nasr, ${ }^{3}$ Shayan Mohammadmoradi, ${ }^{6}$ Aly A Misha'I, ${ }^{7}$ Firas A Annabi, ${ }^{7}$ Ebtesam M Ba-Essa, ${ }^{8}$ Suhad M Bahijri, ${ }^{9}$ Jaakko Tuomilehto, ${ }^{10}$ Linda A Jaber, ${ }^{11}$ William $\mathrm{H}$ Herman, ${ }^{1}$ for the International Group for Diabetes and Ramadan (IGDR)
\end{abstract}

\section{ABSTRACT}

Objective: To determine if individualized education before Ramadan results in a safer fast for people with type 2 diabetes.

Methods: Patients with type 2 diabetes who received care from participating clinics in Egypt, Iran, Jordan and Saudi Arabia and intended to fast during Ramadan 2014 were prospectively studied. Twelve clinics participated. Individualized education addressed meal planning, physical activity, blood glucose monitoring and acute metabolic complications and when deemed necessary, provided an individualized diabetes treatment plan.

Results: 774 people met study criteria, 515 received individualized education and 259 received usual care. Those who received individualized education were more likely to modify their diabetes treatment plan during Ramadan ( $97 \%$ vs $88 \%, p<0.0001$ ), to perform self-monitoring of blood glucose at least twice daily during Ramadan $(70 \%$ vs $51 \%, p<0.0001)$, and to have improved knowledge about hypoglycemic signs and symptoms $(p=0.0007)$. Those who received individualized education also reduced their body mass index $\left(-1.1 \pm 2.4 \mathrm{~kg} / \mathrm{m}^{2} \mathrm{vs}-0.2 \pm 1.7 \mathrm{~kg} / \mathrm{m}^{2}, \mathrm{p}<0.0001\right)$ and glycated haemoglobin $(-0.7 \pm 1.1 \%$ vs $-0.1 \pm 1.3 \%$, $\mathrm{p}<0.0001)$ during Ramadan compared those who received usual care. There were more mild $(77 \%$ vs $67 \%, \mathrm{p}=0.0031)$ and moderate ( $38 \%$ vs $19 \%$, $p<0.0001)$ hypoglycemic events reported by participants who received individualized education than those who received usual care, but fewer reported severe hypoglycemic events during Ramadan ( $23 \%$ vs $34 \%, p=0.0017$ ).

Conclusions: This individualized education and diabetes treatment program helped patients with type 2 diabetes lose weight, improve glycemic control and achieve a safer fast during Ramadan.

\section{INTRODUCTION}

Fasting during the holy month of Ramadan is one of the five pillars of Islam. Muslims who fast during Ramadan abstain from eating, drinking, using oral and injectable

\section{Key messages}

- Those who received individualized education before Ramadan were more likely to modify their diabetes treatment plan during Ramadan, to perform self-monitoring of blood glucose at least twice daily and to have improved knowledge about hypoglycemic signs and symptoms.

- Those who received individualized education reduced their weight and glycated haemoglobin during Ramadan compared to those who received usual care, and were less likely to be hospitalized.

- This individualized education and diabetes treatment program can help patients with type 2 diabetes achieve a safer Ramadan fast.

medications, and smoking from before dawn until after sunset; however, there are no restrictions on food, fluid or medication intake between sunset and dawn. Most people consume two meals per day during Ramadan, one after sunset and the other before dawn. According to religious tenets, Muslims who are pregnant or sick are exempted from fasting. Nevertheless, many Muslims with diabetes choose to fast during Ramadan, thereby creating a medical challenge for themselves and their healthcare providers. It is important that medical professionals be aware of the changes in diet, physical activity and medication-taking associated with fasting during Ramadan, the potential risks (mainly hypoglycemia and hyperglycemia) and approaches to address those changes and to mitigate those risks.

In September 2005, the American Diabetes Association (ADA) published a working group report on the management of diabetes during Ramadan. ${ }^{1}$ This report was updated in August 2010. ${ }^{2}$ Based on the recommendations in these reports, people with type 1 diabetes and pregnant women with diabetes 
should be strongly discouraged from fasting because of the high risk of developing serious and potentially lifethreatening acute metabolic complications. People with type 2 diabetes who wish to fast during Ramadan should receive a full clinical assessment, Ramadan-focused education and individualized treatment recommendations before Ramadan in order to achieve a safer fast.

Since the ADA recommendations were published, two studies have assessed the impact of diabetes education programs on outcomes during Ramadan. The Ramadan Education and Awareness in Diabetes (READ) Study found that attending a structured education program that provided recommendations for physical activity, meal planning, glucose monitoring, hypoglycemia management, and dosage and timing of medications was associated with a statistically significant weight loss of $0.7 \mathrm{~kg}$ and a decrease in the number of hypoglycemic events during Ramadan. ${ }^{3}$ However, this was a small $(n=111$ participants), single site study in which the participants volunteered and the controls declined to receive the education program. The Ramadan Prospective Diabetes Study also found that a structured education program was effective in preventing serious complications of diabetes during Ramadan. This study was also a single site study, the sample size was small ( $\mathrm{n}=110$ participants $)$ and there was no control group for comparison. ${ }^{4}$ A recent study showed that patients who fast during Ramadan can have a significant improvement in glycated haemoglobin (HbAlc) if appropriate adjustments are made to their antidiabetic regimens during Ramadan. ${ }^{5}$

This study was designed as a multination, multicenter, prospective observational study with treatment allocation at the clinic level. Its purpose was to examine if individualized preRamadan education resulted in improved clinical outcomes and a safer fast for people with type 2 diabetes. The individualized education program addressed issues related to meal planning, physical activity, blood glucose monitoring and recognition and management of acute metabolic complications during the month of Ramadan. A physician was also available to perform an assessment and to provide individualized recommendations to change medication management to reduce the incidence of hypoglycemia, reduce fasting and postprandial hyperglycemia and maintain weight or facilitate weight loss during Ramadan.

\section{METHODS}

The study team included diabetes researchers from clinical sites in Egypt, Iran, Jordan and Saudi Arabia, and researchers from the USA. Researchers from the clinical sites were responsible for partnering with clinics willing to participate in the study. A total of 12 clinics were recruited, 4 provided individualized education, 4 provided only usual care and at 4 additional clinics, consecutive patients were invited to be in the intervention group until that group was complete. Thereafter, consecutive patients were invited to be in the control group.
At all clinics, eligible participants were identified as patients who had been diagnosed by a physician with type 2 diabetes, were not currently pregnant and did not have illnesses that were contraindications to fasting (ie, recent myocardial infarction, advanced liver disease end-stage renal disease, cancer, recent surgery, etc). Patients meeting the eligibility criteria who consented to participate were asked to come to the clinic within 2 months before the start of Ramadan (May-June 2014) for a preRamadan assessment, blood draw, survey and either individualized patient education or usual care. They were also asked to return to the clinic within 2 months after the end of Ramadan (August-September 2014) for a postRamadan assessment, blood draw, and survey. Investigators at each clinic obtained approval to conduct the study through their local ethical standards boards and ensured that participants provided informed consent and that patient confidentiality was maintained as required by their local ethical standards boards. Management and analyses of deidentified data were performed at the University of Michigan. The University of Michigan Institutional Review Board reviewed the study and determined that the project was exempt and not regulated since it involved only coded information that could not be linked to a specific individual by the investigator(s) directly or indirectly through a coding system.

For the intervention, each participant received, on average, 2 (range 1-7) $30 \mathrm{~min}$ to $1 \mathrm{~h}$ individualized face-to-face education sessions delivered by dietitians, diabetes specialist nurses or community link workers who were trained by the site investigator. The sessions were conducted either one-on-one or in a group format in the preferred language of the patients. The program addressed issues of meal planning, physical activity, blood glucose monitoring and recognizing and managing acute metabolic complications before and during Ramadan. It was stressed that the diet during Ramadan should not differ from a healthy mixed and balanced diet encouraging slow energy-release foods and minimizing foods high in refined sugars and saturated fat. Regular light and moderate physical activity was encouraged, however, strenuous physical activity immediately before sunset was discouraged because of the risk of hypoglycemia. Patients were educated that blood glucose monitoring did not constitute breaking the fast and were encouraged to test their blood glucose levels. They were also taught to recognize the symptoms of hypoglycemia and hyperglycemia, how to treat those conditions and when to break the fast. The physician provided specific recommendations for changing both the dose and timing of sulfonylurea medications and insulin. In addition, if the physician saw fit, he/she recommended changes to the diabetes treatment regimen so that it was more appropriate for Ramadan and would be weight neutral or help the patient to reduce weight.

Patients receiving only usual care received a copy of the 2010 ADA guidelines for the management of 
diabetes while fasting during Ramadan in English or Arabic. Since these guidelines have been available since 2005, they are likely to have been implemented in these clinics for patients who intended to fast during Ramadan and thus can be considered 'usual care'.

Patients were excluded from the study if they did not know their type of diabetes or reported type 1 diabetes or gestational diabetes $(\mathrm{N}=49)$, did not fast during Ramadan 2014 ( $\mathrm{N}=34)$, or did not complete both a preRamadan and postRamadan survey $(\mathrm{N}=153)$. Data were analyzed for the 774 patients who reported that they had type 2 diabetes, fasted for at least 2 days during Ramadan 2014, and completed both preRamadan and postRamadan surveys. Characteristics of patients at both the preRamadan and postRamadan time points were described in total, and separately for those who received individualized education and those who received usual care using means $\pm \mathrm{SD}$ and $\mathrm{t}$ tests for continuous variables, or number (per cent) and $\chi^{2}$ tests or Fishers exact test for categorical variables.

Knowledge of diabetes risk, hypoglycemic and hyperglycemic symptoms, and actions to take when hypoglycemic were scored on $0-4$ or $0-5$ point scales with 1 point assigned for each correct yes/no answer. Occurrence of mild hypoglycemia was determined by self-report of symptoms of hunger, rapid heart rate, anxiety, tremors, sweating or headache. Moderate hypoglycemia was defined as hypoglycemia that required the assistance of another person, and severe hypoglycemia was defined as hypoglycemia that required medical assistance including emergency room or hospital care, glucagon injection, or intravenous infusion of glucose. Occurrence of mild hyperglycemia was defined as selfreport of symptoms of excessive thirst or increased urination. Severe hyperglycemia was defined as hyperglycemia that required medical assistance or emergency room or hospital care, or treatment with insulin (if not previously using insulin).

Changes in knowledge, weight, body mass index (BMI) and HbAlc from before to after Ramadan were calculated and described in total, and separately for those who received individualised education and those who received usual care. Differences were compared using paired t tests. Analyses were conducted using SAS V.9.3 (SAS Institute, Cary, North Carolina, USA).

\section{RESULTS}

We studied 774 patients with type 2 diabetes attending clinics in Egypt, Iran, Jordan and Saudi Arabia who fasted for $\geq 2$ days during Ramadan 2014. The first Egyptian site was an endocrinology practice that serves $\sim 4000$ adult and geriatric patients in an urban area. The second Egyptian site recruited patients from two clinics, one urban and suburban, in which 2-5 generalists and endocrinologists serve approximately 100 adult and geriatric patients with diabetes each day. The third Egyptian site recruited patients from one urban clinic in which 10 generalists and endocrinologists serve approximately 400 adult and geriatric patients with diabetes each day. In all four of the Egyptian clinics, intervention and control patients were recruited in a sequential manner.

The two clinics in Iran were both located in a large city. The control clinic had five physicians who serve approximately 150 adult patients with diabetes per day. The intervention clinic had nine physicians who serve approximately 100 adult and geriatric patients with diabetes patients per day.

The two clinics in Jordan were located in a large city. In both clinics, endocrinologists serve adult and geriatric patients. The intervention clinic had two physicians who serve approximately 1800 patients with diabetes per year and the control clinic had one physician who serves approximately 900 patients with diabetes per year.

There were two sites in Saudi Arabia. The first that recruited from two urban clinics (one intervention and one control). Each clinic had two generalist physicians that serve a few hundred adult patients with diabetes. The second site in Saudi Arabia recruited two urban clinics in which endocrinologists serve adult patients with diabetes. The intervention clinic had three physicians and serves 120 patients with diabetes per day. The control clinic had eight physicians and serves 250 patients with diabetes per day.

As shown in table 1 , the overall mean age was 48 \pm 10 years, $59 \%$ were female, and over $60 \%$ were at least high school graduates. While there were more women than men who were homemakers or who were not employed ( $36 \%$ vs $25 \%$ ), those who were employed were equally likely to report that they worked indoors or out-of-doors. The mean duration of diabetes was $9 \pm 5$ years. Fifty-six per cent of patients used oral medications and/or non-insulin injectables to treat their diabetes. Twenty-five per cent used oral medications and/ or non-insulin injectables and insulin, $18 \%$ used insulin only and $1 \%$ used diet alone to treat their diabetes. Of those who reported using oral medications and/or noninsulin injectables, $50 \%$ reported using a sulfonylurea.

Almost $75 \%$ of participants reported seeing an endocrinologist for their diabetes management. Most participants reported that they do not usually receive diabetes education before Ramadan (86\%) or during Ramadan $(82 \%)$. Sixteen per cent of people reported that they didn't usually receive advice about fasting during Ramadan. Among those who reported receiving advice, the advice was from a variety of sources including physicians, religious authorities, family members and friends but almost always included advice from a physician.

The intervention clinics recruited 515 participants who received individualized education and the control clinics recruited 259 participants who received only usual care (table 1). The participants who received individualized education were younger than those who received usual care ( 47 vs 51 years old, $\mathrm{p}<0.0001$ ), but the individualized education and usual care participants were similar with respect to sex, education, occupation, 
Table 1 Baseline characteristics of patients who had type 2 diabetes, completed preRamadan and postRamadan surveys, and fasted $\geq 2$ days during Ramadan 2014, stratified by control and intervention group

\begin{tabular}{|c|c|c|c|c|}
\hline Characteristic & Total population & Control group & Intervention group & p Value \\
\hline $\mathrm{N}$ & 774 & 259 & 515 & \\
\hline Age (years) (missing=34) & $48 \pm 10$ & $51 \pm 10$ & $47 \pm 10$ & $<0.0001$ \\
\hline Sex (missing=3) & & & & 0.9268 \\
\hline Male & $315(41 \%)$ & $106(41 \%)$ & $209(41 \%)$ & \\
\hline Female & $456(59 \%)$ & $152(59 \%)$ & $304(59 \%)$ & \\
\hline \multicolumn{5}{|l|}{ Education } \\
\hline Male & & & & 0.2154 \\
\hline Illiterate & $11(3 \%)$ & $7(7 \%)$ & $4(2 \%)$ & \\
\hline Less than high school & $95(30 \%)$ & $32(30 \%)$ & $63(30 \%)$ & \\
\hline High school graduate & $109(34 \%)$ & $35(33 \%)$ & $72(34 \%)$ & \\
\hline Associates degree or higher & $102(32 \%)$ & $32(30 \%)$ & $70(33 \%)$ & \\
\hline Female $($ missing $=1)$ & & & & 0.0323 \\
\hline Illiterate & $38(8 \%)$ & $20(13 \%)$ & $18(6 \%)$ & \\
\hline Less than high school & $127(28 \%)$ & $46(30 \%)$ & $81(27 \%)$ & \\
\hline High school graduate & $171(38 \%)$ & $49(32 \%)$ & $122(40 \%)$ & \\
\hline Associates degree or higher & $119(26 \%)$ & $37(24 \%)$ & $82(27 \%)$ & \\
\hline \multicolumn{5}{|l|}{ Occupation } \\
\hline Male (missing=14) & & & & 0.1783 \\
\hline Employed indoors & $111(37 \%)$ & $34(33 \%)$ & 77 (39\%) & \\
\hline Employed out-of-doors & $115(38 \%)$ & $36(35 \%)$ & $79(40 \%)$ & \\
\hline Homemaker or not employed & $75(25 \%)$ & $32(31 \%)$ & $43(22 \%)$ & \\
\hline Female (missing $=15)$ & & & & 0.7127 \\
\hline Employed indoors & $145(33 \%)$ & $48(32 \%)$ & $97(33 \%)$ & \\
\hline Employed out-of-doors & $137(31 \%)$ & $43(29 \%)$ & $94(32 \%)$ & \\
\hline Homemaker or not employed & $159(36 \%)$ & $57(39 \%)$ & $102(35 \%)$ & \\
\hline Duration of diabetes (years) (missing=8) & $9 \pm 5$ & $10 \pm 6$ & $9 \pm 4$ & 0.0722 \\
\hline Current treatment for diabetes (missing $=5$ ) & & & & 0.1669 \\
\hline Diet and exercise only & $3(1 \%)$ & $2(1 \%)$ & $1(0 \%)$ & \\
\hline Oral medications ( \pm non-insulin injectable) & $434(56 \%)$ & $154(60 \%)$ & $280(55 \%)$ & \\
\hline Oral medications ( \pm non-insulin injectable) and insulin & $192(25 \%)$ & $64(25 \%)$ & $128(25 \%)$ & \\
\hline Insulin only & $140(18 \%)$ & $38(15 \%)$ & $102(20 \%)$ & \\
\hline Provider seen for diabetes management (missing $=45$ ) & & & & 0.3686 \\
\hline Primary care physician & $192(26 \%)$ & $60(24 \%)$ & $132(28 \%)$ & \\
\hline Endocrinologist & $526(72 \%)$ & $190(75 \%)$ & $336(71 \%)$ & \\
\hline Other & $7(1 \%)$ & $1(0 \%)$ & $6(1 \%)$ & \\
\hline None & $4(1 \%)$ & $2(1 \%)$ & $2(0 \%)$ & \\
\hline \multicolumn{4}{|c|}{ Who usually provides advice to you regarding fasting? (missing=20) } & $<0.0001$ \\
\hline Physician and Religious and family/friends & $221(29 \%)$ & $61(24 \%)$ & $160(32 \%)$ & \\
\hline Physician and Religious authority only & $180(24 \%)$ & $46(18 \%)$ & $134(27 \%)$ & \\
\hline Physician only & $154(20 \%)$ & $49(20 \%)$ & $105(21 \%)$ & \\
\hline No one & $119(16 \%)$ & $73(29 \%)$ & $46(9 \%)$ & \\
\hline Physician and family/friends & $59(8 \%)$ & $14(6 \%)$ & $45(9 \%)$ & \\
\hline Religious authority and family/friends & $9(1 \%)$ & $2(1 \%)$ & $7(1 \%)$ & \\
\hline Religious authority only & $7(1 \%)$ & $3(1 \%)$ & $4(1 \%)$ & \\
\hline Family and friends only & $5(1 \%)$ & $2(1 \%)$ & $3(1 \%)$ & \\
\hline \multicolumn{5}{|l|}{ Usually receive diabetes education... } \\
\hline Before Ramadan? (missing=51) & & & & 0.7634 \\
\hline Yes & $103(14 \%)$ & $33(14 \%)$ & $70(15 \%)$ & \\
\hline No & $620(86 \%)$ & $208(86 \%)$ & $412(85 \%)$ & \\
\hline During Ramadan? (missing=57) & & & & 0.0068 \\
\hline Yes & $130(18 \%)$ & $30(13 \%)$ & $100(21 \%)$ & \\
\hline No & $587(82 \%)$ & $208(87 \%)$ & 379 (79\%) & \\
\hline
\end{tabular}

Data are expressed as mean $\pm \mathrm{SD}$ or $\mathrm{N}$ (per cent).

duration of diabetes, current treatment for diabetes, occurrence of previous hypoglycemic and hyperglycemic events and type of provider seen for diabetes management (table 1). Compared to the participants who received usual care, participants who received individualized education had lower body mass index 
(BMI; $30 \pm 4 \mathrm{~kg} / \mathrm{m}^{2}$ intervention vs $31 \pm 5 \mathrm{~kg} / \mathrm{m}^{2}$ control, $\mathrm{p}=0.0097)$ and were less likely to report never monitoring their blood glucose while fasting (9\% intervention vs $18 \%$ control, $\mathrm{p}=0.0021)$. HbAlc was similar $(8.7 \pm 1.3 \%$ intervention vs $8.9 \pm 1.7 \%$ control, $\mathrm{p}=0.2274$ ).

While over $47 \%$ of participants fasted for the entire month, people who received individualized education fasted on average 1 day more than those who received usual care $(\mathrm{p}=0.0257)$. As shown in table 2 , the majority of participants reported receiving diabetes education before Ramadan 2014. However, this per cent was significantly higher for participants receiving individualized education $(98 \%$ vs $84 \%, \mathrm{p}<0.0001)$. In order of decreasing proportion, participants receiving individualized education were more likely to be counseled on recognition and treatment of hypoglycemia, change in

Table 2 Outcomes for patients who had type 2 diabetes, completed preRamadan and postRamadan surveys and fasted $\geq 2$ days during Ramadan, stratified by control and intervention group

\begin{tabular}{|c|c|c|c|c|}
\hline Characteristic & Total population & Control group & Intervention group & p Value \\
\hline $\mathrm{N}$ & 774 & 259 & 515 & \\
\hline Mean number of days fasted & $26 \pm 4$ & $26 \pm 4$ & $27 \pm 4$ & 0.0257 \\
\hline \multicolumn{4}{|c|}{ Did you receive diabetes education before Ramadan? (missing=3) } & $<0.0001$ \\
\hline Yes & $721(94 \%)$ & $216(84 \%)$ & $505(98 \%)$ & \\
\hline No & $50(6 \%)$ & $41(16 \%)$ & $9(2 \%)$ & \\
\hline \multicolumn{5}{|c|}{ For those who received education before Ramadan, the content of the diabetes education included... } \\
\hline Change in medication type & $245(32 \%)$ & $19(7 \%)$ & $226(44 \%)$ & $<0.0001$ \\
\hline Change in medication dose & $313(40 \%)$ & $43(16 \%)$ & $270(52 \%)$ & $<0.0001$ \\
\hline Change in medication timing & $582(75 \%)$ & $165(64 \%)$ & $417(81 \%)$ & $<0.0001$ \\
\hline Change in frequency of glucose monitoring & $392(51 \%)$ & $73(28 \%)$ & $319(62 \%)$ & $<0.0001$ \\
\hline Recognition and treatment of hypoglycemia & 657 (85\%) & $190(74 \%)$ & 467 (91\%) & $<0.0001$ \\
\hline Recognition and treatment of hyperglycemia & $381(49 \%)$ & $76(29 \%)$ & $305(59 \%)$ & $<0.0001$ \\
\hline Recognition of when to break the fast & $389(50 \%)$ & $81(31 \%)$ & $308(60 \%)$ & $<0.0001$ \\
\hline Meal planning & $362(47 \%)$ & $75(29 \%)$ & $287(56 \%)$ & $<0.0001$ \\
\hline Physical activity & $332(43 \%)$ & $60(23 \%)$ & $272(53 \%)$ & $<0.0001$ \\
\hline \multicolumn{4}{|c|}{ Did you receive diabetes education during Ramadan? (missing=15) } & $<0.0001$ \\
\hline Yes & $276(36 \%)$ & $28(11 \%)$ & $248(49 \%)$ & \\
\hline No & $483(63 \%)$ & $229(89 \%)$ & $254(51 \%)$ & \\
\hline \multicolumn{4}{|c|}{ Were you advised by a physician to modify diabetes treatment plan during Ramadan? (missing=27) } & $<0.0001$ \\
\hline Yes & $689(92 \%)$ & $202(83 \%)$ & $487(97 \%)$ & \\
\hline No & $58(8 \%)$ & $41(17 \%)$ & $17(3 \%)$ & \\
\hline \multicolumn{4}{|c|}{ Did you modify diabetes treatment plan during Ramadan? (missing=8) } & $<0.0001$ \\
\hline Yes & $720(94 \%)$ & $222(88 \%)$ & $498(97 \%)$ & \\
\hline No & $46(6 \%)$ & $29(12 \%)$ & $17(3 \%)$ & \\
\hline \multicolumn{5}{|l|}{ How did you modify your treatment plan? } \\
\hline Changed medication type & $204(26 \%)$ & $18(7 \%)$ & $186(36 \%)$ & $<0.0001$ \\
\hline Changed medication dose & $554(72 \%)$ & $162(63 \%)$ & $392(76 \%)$ & $<0.0001$ \\
\hline Changed medication timing & $675(87 \%)$ & $203(78 \%)$ & $472(92 \%)$ & $<0.0001$ \\
\hline Increased frequency of glucose monitoring & $328(42 \%)$ & $72(28 \%)$ & $256(50 \%)$ & $<0.0001$ \\
\hline Changed diet & $306(40 \%)$ & $51(20 \%)$ & $255(50 \%)$ & $<0.0001$ \\
\hline Changed physical activity & $247(32 \%)$ & $34(13 \%)$ & $213(41 \%)$ & $<0.0001$ \\
\hline \multicolumn{5}{|l|}{ During Ramadan, symptoms of... } \\
\hline Mild hypoglycemia* & $571(74 \%)$ & $174(67 \%)$ & $397(77 \%)$ & 0.0031 \\
\hline Moderate hypoglycemia† & $244(32 \%)$ & $49(19 \%)$ & $195(38 \%)$ & $<0.0001$ \\
\hline Severe hypoglycemiał & $208(27 \%)$ & $88(34 \%)$ & $120(23 \%)$ & 0.0017 \\
\hline Mild hyperglycemia§ & $330(44 \%)$ & $111(44 \%)$ & 219 (43\%) & 0.8050 \\
\hline Severe hyperglycemiaๆ & $7(1 \%)$ & $4(2 \%)$ & $3(1 \%)$ & 0.2360 \\
\hline \multicolumn{4}{|l|}{ Hospitalized during Ramadan } & 0.0071 \\
\hline No & 725 (99\%) & $241(98 \%)$ & $484(99 \%)$ & \\
\hline Yes & $7(1 \%)$ & $6(2 \%)$ & $1(0 \%)$ & \\
\hline
\end{tabular}

Data are expressed as mean \pm SD or $\mathrm{N}$ (per cent).

*Mild hypoglycemia: symptoms include hunger, rapid heart rate, anxiety, tremors, sweating, headache.

†Moderate hypoglycemia: symptoms of such severity that the participant required the assistance of another person.

$¥$ Severe hypoglycemia: symptoms of such severity that the participant required professional medical assistance including emergency room or hospital care or placement of an intravenous injection of glucose.

$\S$ Mild hyperglycemia: symptoms including excessive thirst or excessive urination with or without nausea.

TSevere hyperglycemia: symptoms of such severity that the participant required professional medical assistance or emergency room or hospital care, or treatment with insulin (if not taking previously). 
medication timing, change in frequency of selfmonitoring of blood glucose, awareness of when to break the fast, recognition and treatment of hyperglycemia, meal planning, physical activity, changes in medication dose and changes in medication type. Those receiving individualized education were also significantly more likely to report receiving diabetes education during Ramadan 2014 (49\% vs $11 \%, \mathrm{p}<0.0001$ ), to be advised by their physicians to modify their diabetes treatment plan during Ramadan (97\% vs 83\%, p<0.0001) and to modify their diabetes treatment plan during Ramadan ( $97 \%$ vs $88 \%, \mathrm{p}<0.0001)$. In modifying their diabetes treatment plans, participants receiving individualized education most often chose to change the timing of their medication (92\%) and change their medication dose $(76 \%)$ during Ramadan. About half of those receiving individualized education increased their frequency of self-monitoring of blood glucose $(50 \%)$ and changed their diet (50\%), while fewer than half changed their physical activity $(41 \%)$ or changed their medication type $(36 \%)$ during Ramadan.

Participants receiving individualized education were more likely to report symptoms of mild ( $77 \%$ vs $67 \%$, $\mathrm{p}=0.0031)$ and moderate $(38 \%$ vs $19 \%, \mathrm{p}<0.0001)$ hypoglycemia during Ramadan than those receiving usual care. They were, however, less likely to report severe hypoglycemia that required medical assistance, glucagon injection or intravenous infusion of glucose (23\% vs $34 \%, \mathrm{p}=0.0017)$. Symptoms of mild and severe hyperglycemia were equally likely to be reported by those receiving individualized education or only usual care. One of $515(0 \%)$ participants receiving individualized education was hospitalized for intravenous therapy. In contrast, 6 of 259 (2\%) participants receiving usual care reported hospitalizations, 1 for hypoglycemic coma, 2 for intravenous therapy, 1 for hyperglycemia, 1 for palpitations and shortness of breath and 1 for unknown reasons. The proportion of patients receiving individualized education who were hospitalized was significantly less than the proportion receiving usual care $(\mathrm{p}=0.0071)$.

When we examined changes in outcomes, participants receiving individualized education had greater improvement in knowledge of hypoglycemic symptoms, but similar improvements in knowledge of hyperglycemic symptoms and actions to take when hypoglycemic as participants who received usual care (table 3). A greater increase in the frequency of monitoring was seen in participants receiving individualized education compared to those receiving usual care. Eighty per cent of participants receiving individualized education increased their glucose testing frequency during Ramadan compared to $58 \%$ receiving usual care. Of the 385 people receiving individualized education who increased the frequency of monitoring during Ramadan, the majority $(68 \%)$ went from monitoring once a day to twice a day.

There were improvements in weight, BMI and HbAlc from before Ramadan to after Ramadan for participants receiving individualized education or only usual care. These improvements were more marked in participants receiving individualized education. On average, those receiving individualized education lost $2.9 \pm 6.4 \mathrm{~kg}$ during Ramadan compared to a loss of $0.5 \pm 4.6 \mathrm{~kg}$ for those receiving usual care $(\mathrm{p}<0.0001)$. This corresponded to a decrease in BMI of $1.1 \pm 2.4 \mathrm{~kg} / \mathrm{m}^{2}$ and $0.2 \pm 1.7 \mathrm{~kg} / \mathrm{m}^{2}$ in the intervention and control groups $(\mathrm{p}<0.0001)$. HbAlc for participants receiving individualized education improved by $0.7 \pm 1.1 \%$ and $\mathrm{HbAlc}$ for participants receiving usual care improved by $0.1 \pm 1.3 \%$ $(\mathrm{p}<0.0001)$.

Table 3 Changes from baseline to followup for patients who had type 2 diabetes, completed preRamadan and postRamadan surveys and fasted $\geq 2$ days during Ramadan

\begin{tabular}{|c|c|c|c|c|}
\hline Characteristic & Total population & Control group & Intervention group & p Value \\
\hline $\mathrm{N}$ & 774 & 259 & 515 & \\
\hline \multicolumn{5}{|l|}{ Knowledge } \\
\hline Hypoglycemic symptoms (0-5) & $0.06 \pm 1.2$ & $-0.14 \pm 1.1$ & $0.16 \pm 1.2$ & 0.0007 \\
\hline Hyperglycemic symptoms (0-5) & $0.60 \pm 1.3$ & $0.70 \pm 1.3$ & $0.54 \pm 1.3$ & 0.1139 \\
\hline Actions when hypoglycemic $(0-5)$ & $0.14 \pm 1.0$ & $0.15 \pm 1.0$ & $0.14 \pm 1.0$ & 0.8301 \\
\hline \multicolumn{4}{|c|}{ Frequency of glucose monitoring while fasting (missing=104) } & $<0.0001$ \\
\hline Decreased & $31(5 \%)$ & $16(9 \%)$ & $15(3 \%)$ & \\
\hline Stayed the same & $147(22 \%)$ & $63(34 \%)$ & $84(17 \%)$ & \\
\hline Increased & $492(73 \%)$ & $107(58 \%)$ & $385(80 \%)$ & \\
\hline \multicolumn{4}{|c|}{ Of those who increased monitoring... $(n=492)$} & $<0.0001$ \\
\hline Never $\rightarrow$ when symptomatic/ $1 \times / 2 \times$ daily & $60(12 \%)$ & $29(27 \%)$ & $31(8 \%)$ & \\
\hline Only when symptomatic $\rightarrow 1 \times / 2 \times$ daily & $121(25 \%)$ & $27(25 \%)$ & $94(24 \%)$ & \\
\hline $1 \times$ daily $\rightarrow 2 \times$ daily & $311(63 \%)$ & $51(48 \%)$ & $260(68 \%)$ & \\
\hline Weight $(\mathrm{kg})$ (missing=19) & $-2.1 \pm 5.9$ & $-0.5 \pm 4.6$ & $-2.9 \pm 6.4$ & $<0.0001$ \\
\hline BMI $\left(\mathrm{kg} / \mathrm{m}^{2}\right)$ (missing=53) & $-0.8 \pm 2.2$ & $-0.2 \pm 1.7$ & $-1.1 \pm 2.4$ & $<0.0001$ \\
\hline $\mathrm{HbA1c}$ (missing $=43$ ) & $-0.5 \pm 1.2$ & $-0.1 \pm 1.3$ & $-0.7 \pm 1.1$ & $<0.0001$ \\
\hline
\end{tabular}

Data are expressed as mean change $\pm \mathrm{SD}$ or $\mathrm{N}$ (per cent).

$\mathrm{BMI}$, body mass index; HbA1c, glycated haemoglobin. 


\section{DISCUSSION}

Our study supports the use of a preRamadan diabetes education program that includes individualized diabetes treatment recommendations for patients with type 2 diabetes. While participants from both groups were generally not different in terms of their demographic characteristics, duration of diabetes, treatments for diabetes and preRamadan weight and HbAlc levels, those receiving individualized education had greater improvements in weight and HbA1c over the month of Ramadan. Those who received individualized education were also more likely to increase self-monitoring of blood glucose during Ramadan, had greater improvements in knowledge of hypoglycemia and had less frequent severe hypoglycemia.

The individualized preRamadan education program used in this study was based on recommendations from the 2005 and 2010 ADA working group reports on the management of diabetes during Ramadan. ${ }^{1}{ }^{2}$ These reports focused on issues related to meal planning, physical activity, blood glucose monitoring and recognizing and managing acute metabolic complications before and during Ramadan. This type of education program was similar to the program used in the READ study, ${ }^{3}$ which found a mean weight loss of $0.7 \mathrm{~kg}$ in the group that received education compared to a $0.6 \mathrm{~kg}$ mean weight gain in the control group. While we observed weight loss in participants in both groups during Ramadan, the difference was significantly greater in the participants who received individualized education. The READ study also showed a significant decrease in the total number of hypoglycemic events in the group that received education compared to the control group. Our study showed more mild and moderate hypoglycemic events in those who received individualized education. This may have reflected ascertainment bias due to an increase in self-monitoring of blood glucose in participants who received individualized education. There were, however, fewer severe hypoglycemic events and hospitalizations in those who received individualized education. In sensitivity analyses, we found that there were fewer severe hypoglycemic events among those who used and did not use, insulin to treat their diabetes during Ramadan (data not shown).

The education program delivered in the previously reported Ramadan Prospective Diabetes Study ${ }^{4}$ also included elements recommended by the ADA working group and was similar to the education program used in our study. Receiving diabetes education decreased the number of hypoglycemic episodes and most participants did not experience any acute complications of diabetes during Ramadan. Our study extends those results. We also studied patients in a control group who did not receive individualized preRamadan education. This group had more severe hypoglycemic events and more hospitalizations than the participants receiving individualized education. While the participants in our study did not report in great detail the reasons for hospitalization, if we assume 'IV therapy' was for administration of glucose or insulin, then five of the six hospitalizations among those who received only usual care may have been for issues related to hypoglycemia or hyperglycemia.

There were several limitations of our study. First, almost $75 \%$ of participants in both groups reported seeing endocrinologists for their diabetes management. This is likely due to the fact that researchers were responsible for recruiting at the and likely included clinics that had the resources to deliver the interventions. As a result, the clinics we studied may have provided better care than clinics not directed by endocrinologists. Second, although four sites recruited separate intervention and control clinics, four sites sequentially enrolled intervention and control participants form the same clinics. This many have produced contamination bias whereby people in the control group were exposed to the intervention. If so, this would have reduced the apparent impact of the intervention. Third, we did not analyze results of self-monitoring of blood glucose. Although we asked participants in both groups to record at least two blood glucose values daily, we obtained logs from only 279 (54\%) of participants who received individualized education and 52 (20\%) of participants who received only usual care. Owing to the low response rates, we did not include these measurements in the analysis. Fourth, we had to exclude 16\% ( $n=153)$ of the original study population because those participants did not return for the postRamadan study visit. This may have introduced selection bias, as those who did return for a postRamadan study visit may have been more likely to have benefited from participation. In fact, the demographic characteristics of the population that did not return for a postRamadan visit differed from the study population. The non-responders were older (56 \pm 10 years, $\mathrm{p}<0.0001$ ), were more likely to be men $(51 \%$, $\mathrm{p}=0.0212)$, had longer durations of diabetes (12 \pm 8 years), and lower education levels (25\% illiterate, $31 \%$ less than high school, $24 \%$ high school, $21 \%$ associates degree or higher, $\mathrm{p}<0.0001)$.

In conclusion, our study demonstrated that clinics were able to implement programs that provided individualized education for type 2 patients with diabetes before Ramadan and, when needed, physicianrecommended changes in the treatment regimen. Participants who received individualized education had better weight and HbA1c control during Ramadan and were less likely to experience severe hypoglycemia or hospitalization. This individualized education and diabetes treatment program helped patients with type 2 diabetes achieve a safer Ramadan fast.

Author affiliations

${ }^{1}$ Department of Internal Medicine, University of Michigan, Ann Arbor,

Michigan, USA

${ }^{2} E D C$, Center for Diabetes Education, McDonough, GA, USA

${ }^{3}$ School of Medicine, Suez Canal University, Ismailia, Egypt

${ }^{4}$ Alexandria Faculty of Medicine, Alexandria University, Alexandria, Egypt 
${ }^{5}$ Ain Shams University, Cairo, Egypt

${ }^{6}$ Department of Pharmacology and Nutritional Sciences, University of Kentucky, Lexington, Kentucky, USA

'Isalmic Hospital, Amman, Jordan

${ }^{8}$ Dammam Medical Complex, Dammam, Saudi Arabia

${ }^{9}$ Saudi Diabetes Research Group (SDRG), King Fahd Medical Research Center, King Abdulaziz University, Jeddah, Saudi Arabia

${ }^{10}$ University of Helsinki, Helsinki, Finland

${ }^{11}$ Wayne State University, Detroit, Michigan, USA

Acknowledgements WH was supported by Grant Number P30DK092926 (The Michigan Center for Diabetes Translational Research) from the National Institute of Diabetes and Digestive and Kidney Diseases. Publication costs were paid by a grant from the EDC, Center for Diabetes Education,

McDonough, GA. The authors acknowledge the participation and assistance of the physicians from the participating centers including Dr. Sawsan Isa AlLaham, MD (Endocrinologist, Diabetes Center Islamic Hospital, Amman, Jordan) and Dr. Reem M El-Ailah, MD (Resident, Diabetes Center Islamic Hospital, Amman, Jordan)

Contributors LNM researched the data and wrote the manuscript. MI, NMA SHA-K, HRT, GN, SM, AAM, FAA, EMB-E, SMB, JT and LAJ reviewed/edited the manuscript. WHH contributed to the discussion and reviewed/edited the manuscript. LNM is the guarantor of this manuscript and is responsible for the contents of this article.

Competing interests None declared.

Ethics approval Each countries Local Ethical Standards Board; The University of Michigan Institutional Review Board reviewed the study and determined that the project was exempt and not regulated since it involved only coded information that could not be linked to a specific individual by the investigator (s) directly or indirectly through a coding system.
Provenance and peer review Not commissioned; externally peer reviewed.

Data sharing statement Request for deidentified data should be made to $\mathrm{MI}$ and will be evaluated on a case-by-case basis. Deidentified data may be available to researchers with consent of the study team, a signed data use agreement and proper IRB approval.

Open Access This is an Open Access article distributed in accordance with the Creative Commons Attribution Non Commercial (CC BY-NC 4.0) license, which permits others to distribute, remix, adapt, build upon this work noncommercially, and license their derivative works on different terms, provided the original work is properly cited and the use is non-commercial. See: http:// creativecommons.org/licenses/by-nc/4.0/

\section{REFERENCES}

1. Al-Arouj M, Bouguerra R, Buse J, et al. Recommendations for management of diabetes during Ramadan. Diabetes Care 2005;28:2305-11.

2. Al-Arouj M, Assaad-Khalil S, Buse J, et al. Recommendations for management of diabetes during Ramadan update 2010. Diabetes Care 2010;33:1895-902.

3. Bravis V, Hui E, Salih S, et al. Ramadan Education and Awareness in Diabetes (READ) programme for Muslims with Type 2 diabetes who fast during Ramadan. Diabet Med 2010;27:327-31.

4. Ahmedani MY, Haque MS, Basit A, et al. Ramadan Prospective Diabetes Study: the role of drug dosage and timing alteration, active glucose monitoring and patient education. Diabet Med 2012;29:709-15.

5. Siaw MYL, Chew DEK, Dalan R, et al. Evaluating the effect of Ramadan fasting on Muslim patients with diabetes in relation to use of medication and lifestyle patterns: a prospective study. Int $J$ Endocrinol 2014;2014:308546. 